MóNIKA SZENTE VARGa

\title{
EL REFLEJO DE LA PRIMERA GUERRA CRISTERA DE MÉXICO EN HUNGRÍA
}

Una reflexión necesariamente tiene dos componentes: el fenómeno original y la superficie en la que se refleja. Con los cambios de luz, las olas, el movimiento de los animales etc., se va alterando la imagen de un sauce reflejada en el río. Similarmente, la idea húngara de la primera guerra cristera en México es el resultado del reflejo del conflicto mexicano en las aguas -a veces turbias- de la historia moderna de Hungría. Consecuentemente, las personas húngaras que escribieron sobre la guerra cristera en los años 1926-1930 exponen tanto lo que pasaba en México, como la situación interna húngara, hecho digno de análisis histórico. Aparte de proporcionar un breve resumen y evaluación de las fuentes analizadas, que todavía son muy poco conocidas, el objetivo de este escrito es examinar cómo se interpretaron los acontecimientos mexicanos en Hungría, cuáles eran las razones y objetivos de los autores y por último qué lograron.

\section{México}

El poder de la iglesia católica en México disminuyó significativamente en el siglo XIX, recuperándose, solo en parte, durante el porfiriato. La constitución de 1917 afirmó e incrementó los conceptos introducidos por las Leyes de Reforma de 1857. El conflicto armado entre la iglesia y el gobierno estalló en 1926, tras el abierto desacuerdo de la iglesia contra algunos artículos de la constitución, que consideraba como opuestos a la libertad de creencias, protestas que culminaron con la suspensión del culto unilateralmente por parte de la iglesia como respuesta última a las medidas del gobierno (cierre de conventos y escuelas religiosas, deportación de sacerdotes extranjeros, entre otras) tomadas posiblemente con el objeto de crear un cisma religioso. ${ }^{1} \mathrm{La}$ rebelión fue de carácter rural y muchas veces espontánea, aunque la Liga Nacional de la Defensa de la Libertad Religiosa trató de coordinarla. Según estimaciones, el ejército de los cristeros contaba entre 12,000 y 50,000 personas, ${ }^{2}$ y formaba una fuerza militar muy inferior a la del gobierno. Sin embargo el conflicto armado fue alargado por las arbitrariedades perpetradas por ambos lados, de las que llegó a tener fama internacional la ejecución del cura jesuita Miguel Pro. La lucha se concentró en cuatro

${ }^{1}$ Como curiosidad, hay que mencionar, que según la revista Délamerikai Magyarság (Húngaros en América del Sur) la iglesia de los católicos húngaros en la ciudad de México, la del Sagrado Corazón, en la calle de Roma, nunca fue cerrada. En: Délamerikai Magyarság 22/02/1962 p. 6 (referencia de Péter Torbágyi) .

2 12,000-20,000 en Meyer, Lorenzo: El primer tramo del camino. En: Historia General de México Tomo IV, El Colegio de México (México: 1976) p. 119; 50,000 según la página web del Museo Nacional Cristero de México (www.httpl|museocristero.tripod.com.mx) 
Estados y no terminó hasta junio de 1929, cuando se llegó a un acuerdo entre el presidente Emilio Portes Gil y la iglesia, y se reinició el culto. Una fracción no satisfecha con los logros eclesiásticos continuó la lucha (segunda cristera, 1932-38) pero con poco éxito. ${ }^{3}$

\section{Hungría}

La monarquía dual se disolvió en 1918, con el fin de la primera guerra mundial. De ella se formaron seis estados, incluyendo la República de Hungría, declarada en noviembre de ese mismo año, tras una revolución democrática sin lucha armada. Por causa de la inflación y de la disminución del territorio nacional ${ }^{4}$ el poder gradualmente se deslizó de las manos del primer ministro y después presidente Mihály Károlyi, y sus ideas de reformas, referentes por ejemplo a la división de tierras, se quedaron sin ejecución. El 21 de marzo de 1919 un grupo de prisioneros de guerra regresados de tierras rusas tomó el poder con un golpe de estado y declaró a Hungría un estado socialista siguiendo el ejemplo ruso. Fue un tiempo de cambios revolucionarios: se eliminaron los autogobiernos de las provincias y el sistema judicial tradicional; se introdujeron Cortes de urgencia; la guardia roja desempeñó el papel de la policía; se nacionalizaron las fábricas con más de veinte obreros, las tierras agrícolas y la educación. Las fuerzas foráneas de ocupación, los anti-gobiernos ${ }^{5}$ y el descontento de los campesinos al no repartirse la tierra nacionalizada, hicieron fracasar el gobierno comunista en solo 4 meses. Subsecuentemente, con un cambio de 180 grados, se instaló un sistema de orientación derechista que dominó Hungría desde 1920 hasta la segunda guerra mundial Se reinstaló el reinado, pero sin rey, ya que el regreso de los Habsburgos era imposible por la situación internacional. Como consecuencia, la primera persona del país fue el gobernador, Miklós Horthy, cuyo nombre se usa a menudo para caracterizar esta época conservadora.

Uno de los eventos decisivos para Hungría entre las dos guerras mundiales fue el Pacto de Versalles, firmado por Hungría en 1920 en el Gran Palacio de Trianon, por lo que comúnmente en los libros de historia húngaros se le cita como 'Pacto de Trianon'. Como resultado de este acuerdo punitivo derivado de la primera guerra mundial, Hungría pudo retener únicamente $93,000 \mathrm{~km}^{2}$, esto es, el 33\% de su territorio original

\footnotetext{
${ }^{3}$ Resumen hecho con base en Meyer, Lorenzo: El primer tramo del camino. En: Historia General de México Tomo IV, El Colegio de México (México: 1976) p. 111-200 y la página web del museo Nacional Cristero

${ }^{4}$ Los actos militares no terminaron con la disolución de la Monarquía. Los nuevos estados trataron de ocupar los territorios de los vencidos para asegurarse de que, llegado el momento, los redactores del Pacto de Paz definieran las nuevas fronteras según el actual status quo.

${ }^{5}$ Cuestionando la legitimidad del liderazgo bolchevique, se formaron dos grupos de oposición, uno en Szeged y otro en Viena, para coordinar la contrarevolución, quebrantar al gobierno comunista y eventualmente tomar su lugar. Como las composiciones de ambos grupos correspondían a la de un gobierno y los dos lucharon contra el poder central, comúnmente se les llamó anti-gobiernos.
} 
de 282,000 $\mathrm{km}^{2}$-cifra que no incluye la superficie de Croacia ${ }^{6}$ - con $43 \%$ de su población original de 18.2 millones, o sea un total de 7.6 millones de personas. ${ }^{7}$

De los bienes nacionales húngaros solo un $38 \%$ se conservó dentro de las nuevas fronteras. ${ }^{8}$ La reacción inmediata fue una crisis económica muy grave, de la que Hungría pudo salir gracias al préstamo ofrecido por la Sociedad de Naciones, con lo que se estabilizó la situación financiera para 1925-26 y pudo iniciarse un lento proceso de recuperación económica.

Hasta 1848, el catolicismo era la religión oficial en Hungría, aunque existían varias otras iglesias. Con los cambios democráticos llevados a cabo como parte de la guerra de independencia de 1848, se establecieron tres categorías legales para las iglesias: a) reconocida y apoyada gubernamentalmente, b) reconocida pero no apoyada, y c) no reconocida. La iglesia católica romana, junto con la calvinista, luterana, católica griega, antitrinitaria y ortodoxa formaron parte de la primera categoría, a la que se incorporaron los israelitas en 1895. La iglesia católica logró mantener su peso en la vida social, cultural y política gracias a sus bienes, ya que la igualdad legal entre las iglesias no fue seguida por una igualdad de propiedades. En 1918, por falta de tiempo, el gobierno democrático no logró terminar la separación del estado y la iglesia pero el corto período de sistema comunista de 1919 trajo consigo cambios drásticos: la nacionalización de la educación y de los bienes eclesiásticos, la prohibición de la labor educativa de la iglesia y la disolución de las órdenes religiosas. Al término de la breve aventura socialista en agosto de 1919, la iglesia empezaba a recuperarse, pero la reubicación de las fronteras con el Pacto de Trianon (junio de 1920) significó nuevos cambios, positivos y negativos, ante los cuales la iglesia tuvo que adaptarse. El porcentaje de los fieles católicos se incrementó en el país de 49 hasta 65\%, el de los calvinistas de 14 a $21 \%$. Las otras denominaciones retuvieron o perdieron su proporción. De los aproximadamente 1.3 millones de hectáreas de tierra que poseía, la iglesia católica pudo conservar únicamente 500,000 hectáreas, pero aún con esa reducción tenía garantizado un ingreso significativo. ${ }^{9}$ Desde 1920 hasta la segunda guerra mundial la iglesia católica fue una fuerza de consolidación en Hungría, que mantenía nexos cercanos con el gobierno. ${ }^{10}$

\footnotetext{
${ }^{6}$ Croacia perteneció a Hungría desde fines del siglo XI pero simple fue considerada como una entidad separada.

${ }^{7}$ Romsics, Ignác: Magyarország története a XX. században /Historia de Hungría en el siglo veinte/ (Budapest: 1999) p. 145

${ }^{8}$ Romsics, Ignác: Magyarország története a XX. században /Historia de Hungría en el siglo veinte/ (Budapest: 1999) p. 152

${ }^{9}$ Romsics, Ignác: Magyarország története a XX. században /Historia de Hungría en el siglo veinte/ (Budapest: 1999) p. 187-189

${ }^{10}$ Resumen hecho con base en Romsics, Ignác: Magyarország története a XX. században /Historia de Hungría en el siglo veinte/ (Budapest: 1999) p. 99-147 y Gergely, Jenő: Katholikus Egyház, magyar társadalom, 1890-1986 /Iglesia católica y sociedad húngara, 18901986/ (Budapest: 1989) p. 1-73
} 


\section{Fuentes}

La gran mayoría de los materiales utilizados en este análisis proceden de fuentes católicas, principalmente porque los demás órganos escritos en la época no muestran interés hacia el tema de los cristeros. Es conveniente dividir las fuentes en dos: periódicos y otros.

\section{Fuentes hemerográficas}

Los periódicos de los años 1920, de fuerte afiliación católica, A Szív (El Corazón), Hírnök (El heraldo), Magyar kultúra (Cultura húngara), Nemzeti Újság (Revista Nacional) y Új Nemzedék (Nueva generación), ${ }^{11}$ publicaron artículos sobre la situación mexicana con bastante frecuencia. Dado que utilizaron fuentes de información similares y se puede detectar una evidente semejanza entre sus escritos, para este análisis escogí uno solo de ellos: el boletín semanal de la Asociación de la Orden de Jesús: A Szív. Entre febrero de 1926 y febrero de 1930, es decir en cuatro años, equivalentes a 216 números, aparecieron en él aproximadamente 80 artículos relacionados con el conflicto cristero. El año de 1928 llegó a ser el punto culminante del interés húngaro, con 33 artículos, no obstante el extraño lapso de silencio entre septiembre de ese año y febrero del año siguiente. Los escritos cortos aparecieron en tipos pequeños entre las noticias varias, mientras los largos a menudo figuraron en la portada. Los temas más frecuentes eran: noticias de la iglesia católica mexicana, historias de los mártires, la política gubernamental mexicana y su crítica, acusaciones a los masones, protestantes, bolcheviques y judíos por los problemas de México, un ataque contra la prensa no católica húngara por su interpretación de los eventos ocurridos y su falta de interés, y llamamientos de protesta. Estos últimos son característicos de 1928 cuando por ejemplo, se organizó en Budapest una manifestación en pro de la iglesia católica mexicana y de sus fieles, con la participación activa del arzobispo de Esztergom y primado de Hungría, Jusztinián Serédi. ${ }^{12}$ Las últimas noticias de 1929 y las de 1930 ya hablan de una reconciliación entre el clero mexicano y el gobierno, de una paz religiosa. "Como se sabe, el gobierno mexicano se batió en retirada y derogó sus terriblemente crueles decretos anticlericales"13 Según la interpretación particular de la revista, el término del conflicto fue el resultado de la inclinación del gobierno mexicano ante la indudable victoria de la iglesia católica.

Aparte de las noticias, el boletín A Szív publicó una novelita por entregas para niños con el título Ferke Mexikóban (Panchito en México); una adaptación del escrito de A. Erőss ${ }^{14}$ que se publicó originalmente en el boletín de Satu Mare ${ }^{15}$ A Szív. ${ }^{16}$ La

${ }^{11}$ Hírnök era mensual, A Szív semanal, y el resto apareció diariamente.

121884 - 1945. Arzobispo de Esztergom desde 1927, cardenal, especialista en derecho eclesiástico y miembro de la Academia de Ciencias Húngara.

${ }^{13}$ A Szív XIV/ No 47, 20 de julio de 1929. p.1

${ }^{14}$ Posiblemente Alfréd Eröss, n. 1909. Sacerdote, profesor universitario y el miembro de la Academia de San Esteban.

${ }^{15}$ La ciudad formó parte de la monarquía austro-húngara hasta su disolución. Actualmente está en Rumania y se encuentra a pocos kilómetros de la frontera húngara. Su nombre húngaro es Szatmárnémeti. 
historia sobre las aventuras y peripecias del niño húngaro apareció en 27 partes y la serie duró más de medio año, desde septiembre de 1929 hasta marzo de 1930. Desafortunadamente, en cuanto a México no hay más que referencias esporádicas en el escrito. Los edificios y los campos podrían estar en cualquier otro lugar del mundo. Naturalmente el énfasis no fue dar a conocer lo mexicano pero la llamativa falta de detalles y el hecho de utilizar el nombre de Dolores para un niño, lo cual no es muy común, ponen de manifiesto la falta de conocimientos reales sobre México, tanto del escritor como de su adaptador. Sin embargo, la novela cumple con su objetivo principal, que es despertar y fomentar los sentimientos religiosos de los jóvenes que la leen. Podrían admirar y revivir las hazañas de Panchito, quien no solo guarda su fe a pesar de todo: sus escasos años, su soledad, la política amenazadora del gobierno mexicano y las persecuciones, sino que desempeña un papel importante en la victoria de la iglesia y tras ella decide hacerse sacerdote. Un niño, que la revista pone como ejemplo a seguir por los jóvenes húngaros.

Por otro lado, la revista mensual Katholikus Szemle (Diario Católico) merece mención especial por su alto nivel científico, que propiciaba su lectura en los círculos intelectuales. En ella se publicaron dos artículos relacionados con la guerra cristera: el primero bajo el título Az egyház kultúrmunkája Mexikóban (El trabajo cultural de la iglesia en México) por István Hanauer ${ }^{17}$ en 1927, y el segundo, Mi is folyik Mexikóban (Qué es lo que está pasando en México) del sacerdote jesuita Elemér Reisz, aparecido un año después. El escrito de Hanauer es una defensa de la iglesia; un artículo corto de cinco páginas que trata de refutar la opinión de las autoridades mexicanas de que la iglesia católica durante 400 años no ha hecho nada por la cultura del país. Enumera los logros de la iglesia en los campos educativo, social y cultural de México, mientras describe en un tono bastante negativo la situación antes de la llegada de los españoles, destacando aún más el papel positivo de la iglesia católica. El artículo de Reisz es más belicoso. Se divide en tres partes: la lista de los mártires está precedida por los capítulos: Véres egyházüldözés (La persecución sangrienta de la iglesia) y Hösies ellenállás (Resistencia heroica). El escritor caracteriza al presidente Calles como el azote de Dios, un nuevo Atila, quien tiene como objetivo principal arruinar a la iglesia católica. ${ }^{18}$ La enumeración y descripción de los daños sufridos por ésta forman el grueso del artículo que aparte, da un breve resumen de la política del presidente mexicano y de las fuerzas que le secundan, desde un punto de vista peculiarmente húngaro.

Aparte de las publicaciones católicas, otras revistas y diarios también publicaron noticias de la guerra de los cristeros, aunque con mucho menos frecuencia. Entre ellas destacaré la revista ilustrada Tolnai Világlapja (La revista mundial de Tolnai) por su amplio público. En vez de informar y hacer proselitismo como los diarios católicos, ésta trataba más bien de dar noticias y entretener. No faltaban las fotos ni los temas ligeros. Los escritos sobre la guerra de los cristeros sí aparecieron en ella pero no eran las únicas noticias mexicanas, e incluso formaban una minoría en comparación con los otros artículos publicados, por ejemplo, sobre actores y actrices mexicanos. La revista

\footnotetext{
${ }^{16}$ Una publicación semanal en lengua húngara

${ }^{17} 1869$ - 1942. Obispo de Vác, miembro de la cámara alta del parlamento y de la Academia de San Esteban.

${ }^{18}$ Reisz, Elemér: Mi is folyik Mexikóban? En: Katholikus Szemle, 1928 p. 389
} 
primero trató el conflicto como el resultado de las medidas gubernamentales mexicanas cuyo fin era secularizar los bienes de la iglesia. Más tarde, sin embargo, se acercó más al punto de vista de la iglesia católica pero nunca lo adoptó completamente, lo que resultó en varias críticas por parte de las revistas católicas. ${ }^{19}$

\section{Otros}

El grupo "otros" es muy diverso. Encontramos varios géneros aquí, por ejemplo biografía, novela y obra teatral.

La obra teatral juvenil A Mexikói hösök (Los héroes mexicanos) de Berta Gömöri ${ }^{20}$ fue publicada en 1929 como número 94 en la serie Nuestro Teatro. A pesar de ser bastante violenta, ${ }^{21}$ es una historia didáctica escrita para los grupos teatrales aficionados de estudiantes. La siguiente cita da un resumen de la obra:

La obra teatral nos muestra los días de terror durante Calles, mitigando los horrores de la historia, basada en eventos y hechos reales, con escenas graciosas. Los caracteres principales son casi exclusivamente chicas jóvenes. La hija mayor de Calles, Lenora, sigue en los pasos de su padre y odia a los cristianos. La hija menor, Teresia, en cambio, es una católica devota que se está preparando para visitar a las huérfanas de una familia mártir y participar en la misa del fervoroso Padre Pro. Lenora, pretendiendo convertirse a la fe, se entera del secreto e inunda la casa con soldados. El Padre Pro se escapa pero arrestan a las huérfanas. Ya que heroicamente persisten en su religión, las inocentes son ejecutadas. Con ellas muere incluso la hija menor de Calles, con el nombre de Cristo Rey en la boca. La obra termina con una imagen en que volvemos a ver a las heroínas mexicanas como santas glorificadas. ${ }^{22}$

Como se ve incluso en el resumen, la escritora usó libremente el nombre y la figura del presidente mexicano para uno de sus caracteres, lanzando un ataque abierto tanto contra la propia persona de Plutarco Elías Calles como contra su política.

El libro A mexikói vérfürdő (El baño de sangre mexicano) de Jenő Zsámár es una publicación de la revista católica A Szív (El Corazón) y en gran parte es una colección de los artículos publicados en la propia revista. Amén de las historias de los mártires, sus 84 páginas contienen análisis desde el fondo histórico hasta las razones de la guerra de los cristeros, en los que el escritor subraya el papel negativo de los Estados Unidos, ${ }^{23}$ así como de los comunistas, los masones y los protestantes. Como ya es

\footnotetext{
${ }^{19}$ Por ejemplo: Zsámár, Jenő: A mexikói vérfürdő. (Budapest: 1928) p. 79-80, A Szív, XIII / No 8, 22 de octubre de 1927. p. 1-2

${ }^{20}$ Escribió en total tres obras teatrales. La primera (A mexikói hősök) fue seguida por A csodababa (El bebé milagro) y Vérvirágok (Flores de sangre) en 1933.

${ }^{21}$ En la primera escena, por ejemplo, una de las protagonistas está jugando con puras muñecas mutiladas, porque se supone que todas fueron mártires.

${ }^{22}$ Gömöri Berta, contraportada

${ }^{23}$ El papel satánico de los Estados Unidos es uno de los capítulos
} 
tradición en la historia eclesiástica desde Eusebio, ${ }^{24}$ en este caso también se usan citas y documentos ampliamente para apoyar las ideas del autor. En el libro encontramos la traducción de las leyes del 14 de junio de 1926, del artículo 130 de la constitución mexicana, y de la declaración que tuvieron que firmar las personas empleadas por el gobierno. ${ }^{25}$ La parte descriptiva, mas bien pasiva, es seguida por un llamamiento a la acción. Aunque según el escrito la situación parecía más bien desoladora, Zsámár no tuvo dudas en cuanto el resultado final del conflicto, pues terminó con la frase: la iglesia ganará.

Publicado en 1929, el libro Guadalupe apareció con el subtítulo novela mexicana y con un signo de interrogación en lugar del nombre del escritor, el cual después de unas búsquedas bibliotecarias resultó ser el jesuita Béla Bangha. ${ }^{26}$ Su decisión de permanecer anónimo seguramente no fue tomada por un temor de represalias por parte de las personas vivas que critica sino más bien con el fin de atraer un público más amplio que el de los católicos devotos. Además, el libro definitivamente no es una obra de la que hubiera tenido que avergonzarse; según mi juicio es el escrito más profundo y de nivel literario más alto de todos los mencionados en este análisis, que aparte de contar la historia y la conversión de un joven soldado en el tiempo del conflicto cristero, da amplios detalles de la historia, geografía y cultura cotidiana de México en sus 394 páginas. Bangha es más cauteloso y sutil que Berta Gömöri: los personajes negativos de la época que aparecen en la historia no figuran con sus nombres reales sino con los apellidos alterados que, sin embargo, guardan suficiente semejanza con los originales: Obregón es Obreza y Calles es Carres. Asimismo, Bangha describe su obra como novela, lo cual es un buen truco literario para quitar la responsabilidad y reducir el campo de ataque de los posibles críticos, pretendiendo que todo fue ficción en la que, claro, no hay límites. La obra sin embargo se puede considerar como una novela histórica en la que se mezclan los detalles reales y ficticios, y que a pesar de su subtítulo de novela pretende ser más bien una descripción directa de los hechos. Su objetivo es dar a conocer lo que está pasando en México, ${ }^{27}$ con un fin claramente proselitista.

La propagación y profundización de la fe fue también uno de los objetivos principales del libro P. Pro Mihály S. J. és három társa. Mexikói vértanuk (El Padre Miguel Pro, sacerdote jesuita y sus tres compañeros. Mártires mexicanos), publicado en 1928 por la imprenta Korda. El escritor y tal vez el traductor (si la obra original no se escribió en húngaro) son desconocidos. ${ }^{28}$ El libro muestra la vida del Padre Pro, basándose

${ }^{24}$ 263-339. Obispo de Caesaria. Su obra más conocida es La Historia Eclesiástica que narra la historia de la cristiandad desde el nacimiento de Cristo hasta el año 324, en diez tomos..

${ }^{25}$ Esta declaración fue más bien un cuestionario de tema religioso que incluyó preguntas tendenciosas en cuanto a la religión de las personas entrevistadas, su opinión sobre la política del gobierno y sobre la constitución.

${ }^{26} 1880$ - 1940. Personaje eclesiástico y político. Fundador de la revista Magyar Kultúra. En los años 1920 dio varias conferencias en el extranjero incluyendo Holanda, los Estados Unidos y América del Sur.

${ }^{27}$ Las razones básicas de la guerra de los cristeros mencionadas por los caracteres de Bangha son: los Estados Unidos, los líderes mexicanos y desunión interna.

${ }^{28}$ Lo más probable es que el escritor haya sido húngaro, porque en una de sus descripciones escribe: "Roberto Cruz, capitán de la policía, el líder sangriento de la CSEKA mexicana". 
en sus propios escritos, por lo que varias partes aparecen en primera persona. Sin embargo la obra no termina con la muerte del sacerdote, sino continúa con el funeral y con los milagros que se le atribuyen. El objetivo general del libro no es tanto condenar la política del gobierno mexicano, lo que naturalmente hace, sino mostrar la santidad de la vida del Padre y hacer una campaña para que esto sea reconocido por las autoridades eclesiásticas.

Un libro mucho más detallado del mismo género apareció bajo el título Tüzvonalban (En la línea de fuego), de la pluma de Antonio Dragón, promotor de la beatificación del cura. ${ }^{29}$ Publicado originalmente en francés en Montreal, este libro fue traducido a varios idiomas incluyendo inglés, holandés, alemán, italiano, español, portugués, polaco, rumano, esloveno y húngaro. Tuvo dos ediciones en Hungría, en 1936 y 1937.

\section{Razones y objetivos}

Las razones y los objetivos de los escritos húngaros sobre la guerra de los cristeros son diversos y a menudo se entrecubren. En lo general, los artículos y libros mencionados se publicaron para defender a la iglesia y promover la unidad católica, para informar y explicar sobre lo que estaba pasando en México y también para opinar y a la vez influir en asuntos locales usando como pretexto las noticias mexicanas.

Uno de los objetivos principales de escribir sobre este tema fue despertar y mostrar la solidaridad con los católicos en México y proporcionarles, por lo menos, apoyo moral, demostrando así la unidad católica. Partiendo de esta unidad, las medidas del gobierno mexicano se consideraban no solamente un ataque contra la iglesia católica en México, sino contra la iglesia católica en general. Esto fomentó, consecuentemente, el interés extranjero, -por ejemplo húngaro- en apoyar y defender a la iglesia católica mexicana y asimismo a la iglesia católica en general, incluyendo naturalmente a la húngara. Uno de los primeros pasos era refutar las ideas del otro bando, que arrojaban sombra sobre la iglesia. Por ejemplo, el concepto de que la iglesia católica no había hecho nada por la cultura en México por cientos de años. La desmentida se apoyó en dos argumentos. El primero puso énfasis en los logros de la iglesia católica en el campo educativo, mencionando entre otros que la primera imprenta y la primera universidad surgieron antes en México que en cualquier otro lugar en el Nuevo Mundo y que varias de las órdenes religiosas se han dedicado a la enseñanza desde el siglo XVI. El segundo argumento fue que no había existido cultura en México antes de la llegada de la iglesia católica. Contaban la historia de México a partir de la conquista española y consideraban a los Aztecas como un pueblo bárbaro y sangriento que no hacía más que sacrificar gente.

Sus campañas de pillaje fueron temidas aún en tierras lejanas. Celebraban sacrificios humanos con regularidad. Especialmente el dios ma-

Esta es una referencia directa a la policía secreta y máquina de terror soviética, dato que para un húngaro podía ser significativo, pero que tal vez para las personas de otros países geográficamente distantes y que carecen de la experiencia histórica de una revolución bolchevique frustrada, no hubiera tenido el mismo mensaje.

${ }^{29}$ El Padre Pro fue beatificado en 1988. 
yor, Vitzliputzli (sic) ${ }^{30}$ tenía proclividad sangrienta. Quería comer corazones humanos. Y para colmo, estos eran arrancados de cuerpos vivos con bestial crueldad. Solamente la cristiandad puso fin a las horripilantes condiciones bárbaras. ${ }^{31}$

El emperador azteca Ahuitzol ${ }^{32}$ inauguró el templo pagano en México con el sacrificio de 20,000 personas. $^{33}$

Sus descripciones se basaron en las crónicas de los conquistadores. Sin embargo, hay que tomar en cuenta que en dichas crónicas, los españoles trataron de ocultar sus propias matanzas detrás de los sacrificios y encontrar así un buen argumento para tomar el poder, y que los números multitudinarios de sacrificados a los que se refieren, tenían unas dimensiones muy exageradas, como lo plantean análisis computarizados efectuados al respecto. ${ }^{34}$ Uno de los escritos húngaros va más allá de describir a los Aztecas como gente que mató a otras para ofrecerlas a sus dioses. Llega al extremo de escribir que comían carne humana y que no habían tenido ninguna cultura y que no habían construido nada, ni templos, ni pirámides.

Está muy difundida la idea de que México en el pasado tenía una cultura avanzada; se supone que las ruinas de los edificios construidos en la época anuncian la gloria del imperio azteca, derrumbada por la conquista española que, en su turno, hundió a los aztecas desde un nivel cultural alto a la barbarie. Pero los hechos todo lo cuentan de manera diferente. En México sí existió alguna cultura antigua, sin embargo no se erigieron imperios y palacios, solo podemos hablar de una cultura rudimentaria, que llegó a su fin antes de la conquista española precisamente con el arribo de los aztecas desde el norte, ese pueblo bárbaro y caníbal, que acostumbraba celebrar sacrificios humanos. ${ }^{35}$

Negar la existencia de las construcciones prehispánicas en los años 1920 ya es sorprendente, pero no si tomamos en cuenta que el objetivo del autor era realzar el papel beneficioso de la iglesia católica en México. Si afirmamos que en 1500 no había cultura en México, podemos atribuir todos los logros a la iglesia. Por el contrario, si aceptamos que sí hubo una cultura prehispánica, se reduce su papel, sin mencionar nada aún sobre la posibilidad de que los españoles tuvieron que enfrentarse con una cultura muy superior a la suya en muchos aspectos, punto de vista que no apareció en los años 1920 pero es popular en la actualidad.

Aparte de defender a la iglesia y así hacer una campaña más bien pasiva, muchos escritores aprovecharon la oportunidad para hacer proselitismo con la acentuación de la perseverancia, fidelidad y unidad de la gente católica en México y con las historias

\footnotetext{
${ }^{30}$ Huitzilopochtli

${ }^{31}$ Zsámár, Jenő: A mexikói vérfürdő. p. 6

${ }^{32}$ El nombre correcto es Ahuizotl.

${ }^{33}$ Hanauer, István: „Az egyház kultúrmunkája Mexikóban”. En: Katholikus Szemle, 1927, p. 578

${ }^{34}$ Foster, Lynn, Mexikó története. (Szekszárd: 1999) p. 25

${ }^{35}$ Hanauer, István: „Az egyház kultúrmunkája Mexikóban”. En: Katholikus Szemle, 1927, p. 577-578
} 
de los mártires del momento. Intentaron de esta manera ganar más adeptos y al mismo tiempo elevar el sentido religioso de los que ya eran católicos.

En México se han vuelto a repetir las crueldades de las persecuciones anticristianas de los primeros siglos. Todos nos sentimos impresionados por la edificante valentía de los mártires de entonces, y ahora, el heroísmo de los creyentes mexicanos conmueve igualmente nuestra alma. ${ }^{36}$

El ejemplo mexicano nos sirve también de escarmiento. Para nosotros, católicos húngaros, algunas cosas nimias son un problema: que el deber del domingo es pesado, que las leyes matrimoniales son incómodas... En México ¡nada de eso! Allá no se trata de renunciar o no a comodidades pequeñas, sino que vemos a padres de familia subir bravamente al cadalso, e incluso la última gota de fuerza vital de los fieles, con sus lenguas arrancadas, señala hacia el cielo. Católicos húngaros, japrended fuerza de fe de México! ${ }^{37}$

También trataron de advertir a los húngaros que lo que está pasando en México no es un fenómeno aislado, sino que puede pasar también aquí, y que la única manera de evitarlo era participar activamente en la vida política. "La situación mexicana ofrece una lección a todos los católicos. Demuestra adonde pueden llegar los acontecimien-

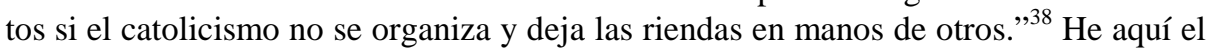
postulado: a través de un hecho concreto en México hemos llegado al catolicismo político húngaro.

Los escritores intentaron informar al público lector, describiendo las noticias y al mismo tiempo interpretando los sucesos. Las razones mencionadas para la guerra cristera se pueden agrupar en cuatro tipos de argumentos.

El primero culpa a los competidores y opositores tradicionales de la iglesia católica en general. Aparecen aquí los protestantes, a quienes acusan de tratar de arruinar la unidad religiosa de México y curiosamente también se cita a los judíos, que básicamente no tienen nada que ver con este asunto específico. Hay artículos que aprovechan para hablar de las consecuencias negativas de la emigración judía a México y del supuesto origen semita de Plutarco Elías Calles.

Calles [...] hace algunos años abrió las puertas de México a los judíos rusos y arribaron 104,000 judíos bolcheviques desde tierras soviéticas. [...] Estos 104,000 judíos en poco tiempo llegaron a tener un gran poder. Ellos forman la directiva de los socialdemócratas y son el apoyo interno de la política de Calles. Él buscó ayuda exterior también y la encontró en la masonería estadounidense y en el protestantismo norteamericano, que le prestó su apoyo incondicional. ${ }^{39}$

El gobierno mexicano en el poder consta de puros masones y depravados aventureros, que roban donde pueden. El presidente es quizá el

\footnotetext{
${ }^{36}$ A Szív, XII/ No 15, 11 de diciembre de 1926. p. 1

${ }^{37}$ A Szív, XIII/ No 28, 25 de febrero de 1928. p. 1

${ }^{38}$ A Szív, XII/ No 13, 27 de noviembre de 1926. p. 1

${ }^{39}$ A Szív, XII/ No 13, 27 de noviembre de 1926. p. 1
} 
más honesto entre todos ellos, pero viéndolo en retrospectiva no podemos olvidar su trayectoria: niño judío, se hizo maestro de escuela primaria, después predicador protestante, luego agitador socialista y finalmente general revolucionario. ${ }^{40}$

Pertenecen a este mismo grupo de señalados como culpables, los masones y los liberales, a quienes la iglesia católica no podía perdonar su idea de que la religión sea asunto privado. Los escritores a menudo combinan varios de estos cuatro grupos en sus descripciones.

La segunda categoría de argumentos acusa a los Estados Unidos. Habla un personaje mexicano:

Intentaron revolucionar el país desde Nueva York. Según el plan, cuando ya todo está hecho un caos en México, el gobierno estadounidense interviene y, en nombre de la humanidad, pone fin a las circunstancias ingratas, naturalmente a cambio de poder adueñarse de este país paraíso. ${ }^{41}$

Los escritores afirman que el interés económico del coloso del norte era mantener el desorden en México, lo que lograron con su peso político y con el control de la venta de armas. "Wilson, el amigo de la paz, como atención muy amable ha mandado 100,000 armas y 50,000 cartuchos a Carranza". ${ }^{42}$ Este y otros artículos critican a los Estados Unidos no solamente por su papel en México sino en Europa. Cuando los mencionan junto con la paz no se refieren tanto a la falta de ella en México como a los 14 puntos de Wilson y al ajuste territorial tras la primera guerra mundial.

Los Estados Unidos [...] querían dominar comercialmente en México y por eso Wilson -a quien podemos dar las gracias por la mutilación de nuestro país- hace tiempo pidió hacer un plan para dirigir la política mexicana. ${ }^{43}$

La razón por la ira húngara no era tanto el conflicto cristero en si, sino la asociación de los Estados Unidos con el tratado de Trianon -aunque no participó en las conferencias de paz- y con la subsecuente pérdida del 67\% del Reinado de Hungría. Con este fondo histórico, los húngaros, como era natural, contemplaron el papel que desempeñaron los Estados Unidos en México desde un ángulo más negativo. Incluso podemos decir, que varios autores utilizaron el conflicto como pretexto para poder condenar abiertamente a ese país. Otra razón para ver y hacer ver mal a los Estados Unidos fueron los relatos que afirmaban que los fines del Tío Sam con el conflicto cristero eran conquistar todo México, lo que antes no podían porque el vecino era demasiado unido cultural y religiosamente. Pero de todas maneras ya habían tomado

\footnotetext{
${ }^{40}$ A Szív, XI/ No 48, 31 de julio de 1926. p. 1

${ }^{41}$ Zsámár Jenő: A mexikói vérfürdő. p. 7

${ }^{42}$ Dragon, Antonio: Tüzvonalban. (Budapest: 1936) p.24. En realidad, esta es una de esas noticias que habría que confirmar en cuanto a su exactitud, pues interpretada así, tan a la ligera, francamente mueve a risa, pues la mitad de las armas señaladas tendría un solo cartucho, y el resto no servirían para nada.

${ }^{43}$ A Szív, XI / No 48, 31 de julio de 1926, p.1
} 
el 50\% del territorio de México en el pasado, hecho que tampoco ayudó a crear una imagen positiva de los Estados Unidos en la sociedad húngara que acababa de pasar por el cambio de sus propias fronteras.

El tercer tipo de argumentos contiene razones básicamente locales, surgidas de la experiencia histórica húngara desde los principios del siglo veinte y que en realidad tienen muy poco que ver con México y la guerra cristera. Me refiero a los socialdemócratas y los bolcheviques.

La elección de Obregón no fue el deseo del pueblo sino la obra de Calles. La plebe socialdemócrata y masona simplemente se impuso y logró su victoria con terror. Fue una elección similar a la que tuvimos aquí cuando la chusma roja "eligió” a Mihály Károlyi como presidente. ${ }^{44}$

Otros añaden que Calles quería establecer una República Socialista que hubiera abarcado América Central, lo que fue una referencia directa a la República de Consejos que se hizo aquí en Hungría en 1919 con efectos espantosos.

Calles fraguó el plan de difundir el comunismo a Guatemala, El Salvador, Honduras y Costa Rica. E incluso quiso incorporar a otros países pequeños, como Venezuela, Colombia (sic), Haití, Santo Domingo ${ }^{45}$ y la Cuba americana, en un estado socialista centroamericano de Consejos, naturalmente bajo mando mexicano. ${ }^{46}$

La aparición de los socialdemócratas y de los bolcheviques en los textos tenía un fin doble. Como sinónimos del terror en la mente católica húngara, se usaron para describir eventos en México - aunque directamente no tenían nada que ver - y al atribuirles un papel en los hechos desafortunados de México, se podía llamar la atención de que siguen siendo peligrosos y que aquí en Hungría hay que cuidarse especialmente.

No solamente ejercen tutela sobre nosotros, sino abusan y nos reducen a una colonia. Y fomentan todas las inquietudes internas, e incluso apoyan entre nosotros la guerra religiosa, el bolchevismo (sic) y todo tipo de revolución, para que no haya orden ni paz en nuestro país y no tengamos tiempo y manera de devolver el golpe a la mano que está hurgando en nuestras bolsas. ${ }^{47}$

A los escritores no les pareció difícil mencionar a los bolcheviques y a los Estados Unidos juntos como razones para la guerra cristera. Para ellos no eran enemigos y antónimos sino sinónimos que personificaron al villano de la película.

La cuarta categoría de argumentos se centra alrededor del carácter de los líderes mexicanos. Los escritores no escatiman adjetivos y comparaciones negativas en las que juntan todo el arsenal adquirido en los puntos anteriores. Calles aparece entonces

\footnotetext{
${ }^{44}$ A Szív, XIII/ No 46, 14 de julio de 1928, p. 1

${ }^{45}$ Se refiere a la República Dominicana.

${ }^{46}$ Zsámár, Jenő: A mexikói vérfürdő. p. 21

${ }^{47}$ Bangha, Béla: Guadalupe. (Budapest: 1929) p. 236-37
} 
como "el presidente mexicano que odia a la iglesia”48 “el Nerón masón”49 "el Nerón de la edad moderna, el tirano sangriento del baño de sangre mexicano"50 "el cruel dictador socialdemócrata y masón" 51 que llegó y se mantiene en el poder, naturalmente, con la ayuda de los Estados Unidos, etc. Calles fue mencionado tantas veces que a pesar de la tirada corta de la mayoría de las fuentes, una persona húngara que leía la prensa con regularidad en los años 1920, seguramente podía asociar su nombre con México. Otros políticos mexicanos mencionados negativamente incluyeron a Benito Juárez, Lerdo de Tejada, Madero, Villa, Carranza, Obregón e inclusive a Porfirio Díaz.

\section{Resultados}

Paralelamente y como resultado de las noticias, se organizaron protestas y reuniones para llamar la atención hacia el conflicto en México, primero como parte de campañas internacionales y posteriormente en forma local. Por ejemplo, siguiendo las instrucciones del Papa en las que pidió que el día 1 de agosto de 1926 se rezara en cada iglesia católica por los fieles mexicanos y que el sacerdote hablase de la situación mexicana en el sermón. El tercer domingo de adviento de 1927 se declaró día mexicano, en el que los miembros de las congregaciones en el mundo participaron en un sermón común, en solidaridad con los católicos mexicanos. El año 1928 trajo consigo una intensificación de las actividades, especialmente en los meses de febrero y marzo. El 19 de febrero se organizó una protesta en Budapest con la participación activa de varios personajes principales de la vida política y eclesiástica húngara. Pronunciaron discursos el primado Jusztinián Serédi, el Dr. Aladár Krüger, miembro del parlamento, István Haller, ex-ministro, Béla Bangha, padre jesuita y el conde Albert Apponyi. ${ }^{52}$ La protesta, en la que participaron varios miles de personas ${ }^{53}$ exigió la intervención del gobierno húngaro frente a la Sociedad de Naciones. Tres días después, utilizando proyecciones, Béla Bangha dio una presentación sobre los sucesos mexicanos en el antiguo edificio del Parlamento. La presentación tuvo que ser repetida el 22 de marzo por el gran número de gente interesada. Las iniciativas de 1928 ya eran más bien locales y se centraron en Budapest.

Las protestas junto con los artículos y otros escritos lograron despertar el interés hacia México en Hungría y aunque fuese por un período muy breve, la cuestión mexicana llegó a nivel político. El 30 de abril de 1928 la provincia de Győr-MosonPozsony tomó la resolución de que había que protestar formalmente ante la Sociedad de Naciones. En ella acentuaban la solidaridad con México y las similitudes entre el pueblo mexicano y el húngaro. "Nosotros, que ya hemos pisado el camino de los mártires y llevamos la cruz de nuestra propia mutilación, podemos apreciar más el signifi-

\footnotetext{
${ }^{48}$ A Szív, XII/ No 46, 16 de julio de 1927, p.3

${ }^{49}$ A Szív, XII/ No 18, 1 de enero de 1927, p. 1

${ }^{50}$ A Szív, XIII/ No 45, 7 de julio de 1928 p. 1

${ }^{51}$ A Szív, XIII/ No 49, 4 de agosto de 1928 p. 1

521846 - 1933. Político, ministro, latifundista y miembro de la Academia de Ciencias Húngara. Líder de la delegación húngara en los tratados de paz de la primera guerra mundial.

${ }^{53}$ Pesti Hírlap (Diario de Pest), L / No 42, 21 de febrero de 1928, p. 8 y Új Nemzedék X / No 42, 21 de febrero de 1928 p. 5
} 
cado del consuelo de la comprensión en las horas de persecución y abandono. ${ }^{„ 54} \mathrm{La}$ resolución se envió a las otras provincias y ciudades mayores para que la apoyasen. En total, contando a la propia provincia de Györ-Moson-Pozsony, firmaron 16 de las 25 provincias y cuatro ciudades mayores, lo que significa el 64\% de las provincias y el $40 \%$ de las ciudades. El interés y el entusiasmo del momento eran debidos parcialmente a un factor nuevo, el político. Con la disolución de la monarquía dual, Hungría logró su independencia pero se redujo a un país insignificante, sin peso político alguno, aspecto que fue empeorado aun más por su aislamiento. El tratado de amistad firmado con Mussolini en 1927 se celebró fervorosamente como la salida del aislamiento total y el principio de algo nuevo. Surgió una gran oleada de auto-confianza. Hungría empezó a profesar abiertamente su política revisionista de reestablecer las fronteras existentes antes de 1918 y no faltaban quienes pensaron que el país ya era capaz de alterar la política mundial. La idea de la protesta ante de la Liga de Naciones fue tanto con el objetivo de defender a los católicos mexicanos como con el de mostrar ante el mundo que Hungría es fuerte y puede tener iniciativas en asuntos internacionales. La propuesta llegó a las dos cámaras del Parlamento y primero la trabajaron los comités. Dependía de ellos si el asunto llegaba a la reunión plenaria. En el caso de la cámara baja, no encontré ninguna mención de México en la reunión plenaria, así que con toda seguridad, el asunto se atrancó a nivel de comité. En el caso de la cámara alta, la cuestión mexicana sí apareció ante la reunión plenaria en la que Károly Huszár, ex-primer ministro ${ }^{55}$ pronunció un discurso a favor. ${ }^{56}$ La propuesta del comité, que fue una versión alterada de la que mandaron las provincias, se aceptó. Pidieron al ministro de asuntos exteriores ${ }^{57}$ que en tiempo y manera adecuada, pronunciase la protesta de la cámara alta del Parlamento húngaro. Ya no mencionan a la Sociedad de Naciones, posiblemente porque ellos sabían que la Liga no era un elixir contra todos los males, e incluso había problemas con su funcionamiento. Además, México no era miembro, y las posibilidades de Hungría en dicho organismo eran muy escasas. De todas maneras, la puerta en ese sentido quedaba abierta al encomendarse el punto al entendimiento del ministro de asuntos exteriores. Desafortunadamente no hubo un seguimiento inmediato y no podemos saber si Hungría hubiera realmente protestado en forma oficial y exactamente cómo, ya que la fecha de la resolución es febrero de 1929, y la primera guerra cristera termina hacia junio de ese año. La cuestión mexicana se eliminó así del orden de día en Hungría.

\section{Obras seleccionadas}

\footnotetext{
${ }^{54}$ Borsod-Abaúj-Zemplén megyei levéltár (Archivo de la comarca de Borsod-Abaúj-Zemplén) IV. B. 1906. Miskolc város polgármesteri hivatalának iratai (documentos de la ciudad de Miskolc) 17542 / 1928.

551882 - 1941. Político cristiano-socialista. Ministro de educación, primer ministro (noviembre de 1919- marzo de 1920).

${ }^{56}$ sesión 54 de la cámara alta, 14 de febrero de 1929

${ }^{57}$ Lajos Walko
} 


\section{A.) fuentes primarias}

libros:

Bangha Béla: Guadalupe. Mexikói regény. Pallas Rt.(Budapest: 1929) 394p.

Dragon Antonio: Tüzvonalban. P. Pro S. J. élete. Manréza. (Budapest: 1936) 128

p.

Gömöri Berta: A mexikói hösök. Gyermekdráma öt felvonásban. Szalézi művek (Rákospalota: 1931) 39p.

P. Pro Mihály S. J. és három társa. Mexikói vétanúk. Korda Rt (Budapest: 1928) 51p.

Zsámár Jenő: A mexikói vérfürdő. Viva Cristo Rey! (Budapest: 1928) 84 p.

artículos e historias por entregas, clasificadas según las revistas:

Katholikus Szemle 1927: Hanauer, István: Az egyház kultúrmunkája Mexikóban p. 577-581, 1928: Reisz, Elemér: Mi is folyik Mexikóban p. 389-415

Pesti Hírlap 1928: 19, 21 de febrero, 23 de junio

A Szív (szatmárnémeti) 1929: 3 de febrero, 7 de abril, 5 de mayo

A Szív (szatmárnémeti): Erőss A.: Csodálatos Ferke (historia por entregas para niños) 1929: 3, 10, 17 de febrero, 3, 10, 17, 24 y 31 de marzo, 7, 14, 21 y 28 de abril, 5 de mayo y 30 de junio/ Los demás ejemplares faltan en la biblioteca nacional húngara. /

A Szív: Ferke Mexikóban (adaptación del szatmári Szív) 1929: 14, 21, 28 de septiembre, 5, 12, 19, 26 de octubre, 2, 9, 16, 23 de noviembre,7, 14 y 21 de diciembre, 1930: 4, 11, 18, 25 de enero, 1, 8, 15, 22 de febrero, 1, 8, 15, 22 y 29 de marzo. /teljes/

A Szív 1926: 13 de febrero, 8, 15 de mayo, 3, 10, 31 de julio,7, 14, 28 de agosto, 4, 25 de septiembre, 8, 23 de octubre, 13, 27 de noviembre, 4 y 11 de diciembre. 1927: 1, 8, 29 de enero,5 de marzo, 11 de junio, 9, 16 de julio, 17 de septiembre, 22, 29 de octubre, 10 y 31 de diciembre. 1928: 14, 28 de enero, 4, 18, 25 de febrero, 3, 10, 17, 24, 31 de marzo, 7, 14, 28 de abril, 5, 19 de mayo, 2, 9, 16, 23 de junio, 7, 14 de julio, 4 y 11 de agosto. 1929: 9, 30 de marzo, 13, 20 de julio, 10, 17 de agosto, 7 de septiembre, 5, 12 de octubre, 9 y 23 de noviembre. 1930: 1, 8 y 22 de febrero.

Tolnai Világlapja 1926: 11 de agosto, 8 de septiembre, 6 de octubre, 1927: 28 de diciembre, 1928: 18 de enero

Új Nemzedék 1928: 17, 19, 21 de febrero

$\underline{\text { otras }}$

Archivo de la comarca de Borsod-Abaúj-Zemplén IV. B. 1906. Documentos de la ciudad de Miskolc 17542 / 1928.

Felsőházi Napló (Diario de la Cámara Alta Húngara), sesión No 54, 14 de febrero de 1929

Az 1926 október 8-án Budapesten a hercegprímási palotában tartott püspökkari érte- 
kezlet. (Conferencia de los obispos el 8 de octubre de 1926 en la casa del primado en Budapest) En: A magyar katolikus püspökkari tanáçskozások története és jegyzőkönyvei (La historia y los protocolos de las reuniones obispales católicas húngaras), tomo I ed.: Beke, Margit. (Budapest: 1992) p. 179

\section{B.) fuentes secundarias}

Gergely, Jenő: Katholikus egyház, magyar társadalom, 1890-1986. (Budapest: 1989) p. $1-73$

Meyer, Lorenzo: El primer tramo del camino. En: Historia General de México Tomo IV, el Colegio de México (México: 1976) p. 111-200

Meyer, Jean: La vida cotidiana (tomo III) 95p. y Grandeza mexicana (tomo IV) 95p. de la colección La Cristiada. (México: 1997)

Romsics, Ignác: Magyarország története a XX. században (Budapest: 1999) p. 99147 


\section{SZENTE VARGA MóNIKA}

\section{A Cristero-felkelés magyar tükörben}

A tanulmány a mexikói Cristero-felkelés magyarországi visszhangjával foglalkozik, 1926 és 1930 között megjelent sajtócikkek és egyéb írásos források alapján. Ezekből nemcsak az derül ki, hogy a szerzők szerint ebben az időszakban mi zajlott Mexikóban, hanem az is, hogy mi történt illetve mi történik Magyarországon, hiszen ezek az események alapján értékelik a mexikói híreket. A források rövid bemutatása és értékelése után a tanulmány a Cristero-felkeléssel kapcsolatos írások Mexikó-képét vizsgálja, illetve ezen művek megjelenésének okait és céljait, végezetül pedig azt, hogy a kitüzött célokból mi valósult meg.

A gyakran elválaszthatatlanul egymásbafonódó okok és célok közül mindenképpen ki kell emelni egyrészről a katolikus egyház védelmét, a katolikus egység előremozdítását, és a magyar politikai katolicizmust, másrészről pedig a mexikói történésekről való tájékoztatást, amelyet ugyanakkor a szerzők gyakran ürügyként használtak fel arra, hogy helyi, például a magyar politikai élettel kapcsolatos kérdésekben véleményt nyilvánítsanak. Az 1926 februárjától meginduló magyar sajtóreakció - elsősorban katolikus sajtó, 1928-tól szélesedett ki: megjelentek egyéb írásos mủvek (színdarab, regény, életrajz) és előadásokra illetve egy nagyobb utcai demonstrációra is sor került. 1928 tavaszától a konfliktus 1929-es rendeződéséig, a Cristero-felkelés Magyarországon - hacsak rövid időre is - politikai kérdés lett. A mexikói katolikusok iránti szimpátia, illetve a megyék külpolitikai ambíciói révén tárgyalta a kérdést például a Felsőház is. 
Los autores de los ensayos presentados en este número de ACTA HISPANICA son participantes del programa de $\mathrm{PhD}$ de la historia moderna y contemporánea en la Universidad de Szeged.

A tanulmány szerzői a Szegedi Tudományegyetem modernkori történeti doktori programjának hallgatói. 